\title{
Predictors of pharmacophobia
}

\section{Ana Petelinšek, ${ }^{1}$ Anita Lauri Korajlija ${ }^{2}$ \\ 'SELECTIO Ltd., Zagreb; ${ }^{2}$ Department of Psychology, Faculty of Humanities and Social Sciences, University of Zagreb, Croatia}

\begin{abstract}
Recent studies estimate that between $30 \%$ to $50 \%$ of the population does not adhere to their prescribed therapies, and one of the reasons is pharmacophobia. Pharmacophobia is a fear of medication and a negative attitude toward drugs in general. The aim of this study was to determine predictors of pharmacophobia. 700 participants participated in the study, of which $80.9 \%$ were female. The age of the participants ranged from 19 to 62 years $(M=26.5$, $\mathrm{SD}=7.41$ ). The instrument consisted of several questionnaires measuring attitudes toward drugs, beliefs about medicine, emotional disgust, medication form preference, tendency for alternative medical habits and the likelihood of believing in conspiracy theories. Also, the demographic data was collected. The research was conducted through an online survey. The results showed that out of the total number of participants, $20.3 \%$ evaluated themselves as pharmacophobic, and $79.7 \%$ as pharmacophilics. Given the goal of the study, the results obtained suggest that one of the predictors of pharmacophobia is the tendency to believe in conspiracy theories, where the higher inclination to believe in conspiracy theories leads
\end{abstract}

Correspondence: Ana Petelinšek, Petrova 60, 10000 Zagreb, Croatia. Tel. : +385.919269088.

E-mail ana.petelinsek@gmail.com

Key words: fear of medication, health behavior, medicines, phobia, drug attitude

Contributions: AP data collecting and analyzing, manuscript writing; ALK, data analyze and manuscript reviewing.

Conflict of interest: The authors declare no potential conflict of interest.

Funding: None

Availability of data and materials: All data and materials are available within the text.

Ethics approval and consent to participate: The study has been approved.

Informed consent: Informed consent has been received.

Received for publication: 27 January 2020

Accepted for publication: 7 April 2020

This work is licensed under a Creative Commons AttributionNonCommercial 4.0 International License (CC BY-NC 4.0).

(C) Copyright: the Author(s), 2020

Licensee PAGEPress, Italy

Health Psychology Research 2020; 8:8853

doi:10.4081/hpr.2020.8853 to greater pharmacophobia. Furthermore, the preference for solid drug forms and drugs that are intended for usage through the body cavity also contribute to an explanation of pharmacophobia in a way that pharmacophobic persons do not have a preference toward said medication forms. The predictor that contributes the most in the explanation of pharmacophobia is a negative belief in drugs, suggesting that a person with an expressed negative attitude to medication will probably not adhere to prescribed therapies by doctors.

\section{Introduction}

Although new innovative medicine is being discovered daily, not everybody is inclined to take medication. Accordingly, we can distinguish two groups of people: pharmacophilics and pharmacophobics (De las Cuevas and Peñate, 2015; Gazerani, 2017). Pharmacophilics are people who have no qualms with taking medication and who are willing to take medicine if needed, while on the other hand, pharmacophobia refers to the fear of taking medication or accepting any medical treatment (Gazerani, 2017). Pharmacophobics have a negative attitude toward drug usage and although pharmacophobia has not yet been sufficiently investigated, it is considered that one of its predictors could be a history of adverse drug reactions due to inappropriately attributed drugs or medication overdoses (De las Cuevas and Peñate, 2015).

Given the fact that pharmacophobia is defined as a fear of taking medications, as with all other phobias, there are some consequences regarding the quality of the person's life. Pharmacophobia might lead to improper usage of medication, the complete absence of medicine consumption and relapse of a disorder or disease, which has a negative impact on a person's quality of life (Gazerani, 2017; Christudas et al., 2016). Although drug consumption has become widespread in today's society, several studies estimate that approximately $30 \%$ to $50 \%$ of the population does not adhere to their prescribed therapy. One of the reasons for inadequate medication adherence is pharmacophobia (Vermeire, Hearnshaw, Van Royen and Denekens, 2001). Moreover, since the correlation between pharmacophobia and nonadherence to prescribed therapies has been identified (Gazerani, 2017; Christudas et al., 2016), the question that surfaces is what is the reason for pharmacophobia appearance. As a possible reason, we might consider physical fear of medication, which on the one hand may include fear of the substances that are present in the drug or, on the other hand, it may be a fear of all medication treatments in general. In addition to the fear, a potential reason may lie in the lack of confidence in the medical system which includes a negative attitude toward medicine, medication and all treatments.

Furthermore, people with a strong belief that taking medication is obligatory in maintaining their health are more likely to follow the prescribed instructions as opposed to people who have expressed concern about medication and who are actively thinking about the dangers and long-term consequences that medication can 
cause (Horne and Wienman, 1999). It has been shown that pharmacophobics are more likely to express their distrust in medicines and experts, which might indicate a correlation with a belief in conspiracy theories (Sibitz, Katschnig, Goessler, Unger i Amering, 2005). People who are inclined to believe in conspiracy theories, especially conspiracy theories related to the pharmaceutical industry, are more likely to disregard the doctor's prescription and turn toward alternative medicine (Bogart, Galvan, Wagner and Klein, 2011; Oliver and Wood, 2014).

Pharmacophobics do not trust medication and often believe that the population is consuming medication on an extreme level. They often have an attitude that doctors are prescribing and overattributing medications, even though sometimes medication is not the best possible solution. Additionally, they also find that the medicines have too many side effects that might endanger their health in the long term.

In addition to the difference in attitude toward medicine and general distrust, some research showed the demographic difference between pharmacophobics and pharmacophilics. Pharmacophobics have been found to be significantly younger than pharmacophilics and are more likely to be male (Gazerani, 2017). On the other hand, differences in educational level are not straightforward. Some findings demonstrated that pharmacophobics have higher education than pharmacophilics (De las Cuevas and Peñate, 2015; Rettenbacher, Burns, Kemmler and Fleischhacker, 2004), while other findings indicated no significant difference (Christudas et al., 2016). Most of the research has been focused on a specific medical condition or on psychiatric disorders, and in those studies it has been found that pharmacophobics are more likely to suffer from anxiety and personality disorder, whereas in pharmacophilics, schizophrenia and bipolar disorder is more common (De las Cuevas and Peñate, 2015).

Given that no studies were found that were based solely on the predictors of pharmacophobia and that pharmacophobia is detected as a predictor of non-adherence to therapy, it is important to recognize what leads to pharmacophobia in order to be able to intervene on time and to increase the success rate of treatments. For this reason, the aim of this study was to identify predictors of pharmacophobia. In explaining the variance of pharmacophobia, the contribution of sociodemographic characteristics (gender, age, education level), medication form preference, tendency toward alternative medical habits, likelihood of believing in conspiracy theories, fear of blood, injections and death, as well as attitude toward drugs has been examined. It was expected that the male gender, younger age and higher education level will positively contribute in explaining the variance of pharmacophobia. Also, lower preference of all forms of medications, especially the solid drug forms, was expected to be one of the predictors, as well as a greater propensity for alternative medicine and conspiracy theories, and a pronounced fear of blood, injections and death. In addition, negative beliefs about all medication were expected to be the strongest predictor of pharmacophobia.

\section{Materials and Methods}

The study was conducted on a sample of 700 participants, with $80.9 \%$ being female. The age of participants ranged from 19 to 62 years $(\mathrm{M}=26.5, \mathrm{SD}=7.41)$. Regarding the level of education, $39.7 \%$ of participants have a high school degree, $26.7 \%$ have an undergraduate degree, $30.6 \%$ have a graduate degree and $3 \%$ of the participants have a postgraduate degree. Furthermore, the study was conducted through an online Google Forms Survey posted on
Facebook over a two-week period as well as via sending the survey to direct potential participants.

\section{Instruments}

The instrument consisted of several questionnaires measuring attitude toward drugs, beliefs about medicine, emotional disgust, medication form preference, tendency toward alternative medical habits and the likelihood of believing in conspiracy theories. Also, the demographic data was collected.

The medication form preference questionnaire was designed for the purpose of this research and was based on the division of medication by its form. Pharmaceutical forms for internal use are divided into liquid forms (syrups, oral drops), solid forms (powders, granules, capsules, tablets) and forms intended for introduction into body cavities (drops and sprays) (Bradamante, Klarica and Šalković - Petrišić, 2008). The degree of medication form preference is measured by the Likert scale, with 1 indicating "No preference" and 5 indicating "Very strongly prefer". The questionnaire consists of 11 items, which include three categories. Liquid drug forms include two items, solid drug forms include five items, while forms intended for introduction through body cavities include four items. Cronbach alpha for liquid forms sub-scale is $\alpha=.73$, for solid forms sub-scale is $\alpha=.77$ and for forms intended for introduction into body cavities is $\alpha=.82$.

Hogan Drug Attitude Inventory (DAI) (Hogan, Awad and Eastwood, 1983) is an instrument that has 30 items in its original form, but for the purpose of this study five items were excluded that were solely related to attitudes toward drugs for psychiatric disorders. They were excluded as the research did not focus on attitude and the fear of specific medication. The revised Hogan Drug Attitude Inventory used in this study consists of 25 items where the participants expressed their agreement with the statements in "true" or "false" terms. The sum result was computed. Cronbach alpha of the revised scale is $\alpha=.71$.

Beliefs About Medicine Questionnaire (General - BMQ) (Horne, Weinman and Hankins, 1999) consists of 8 items and is focused on medication beliefs in general. It is divided into two subscales. The General - Harm sub-scale assesses beliefs about harmfulness of medications (eg "Medicines do more harm than good") and the General - Overuse sub-scale addresses the concept of doctors' over-prescription and their excessive trust in medication (eg "Doctors place too much trust on medicines"). The items are scored on a 5-point Likert scale (with 1 indicating "strongly disagree" and 5 indicating "strongly agree") with the score ranging from 4 to 20, where the larger score corresponds to greater negative belief about medications. Cronbach alpha in this study is $\alpha=.85$.

The Disgust Emotion Scale (DES) consists of 30 items measuring five different sources of disgust - disgust toward animals, injections \& blood, death, spoiled food, unpleasant odors (Walls i Kleinknacht, 1996; Olatunji, Sawchuk, de Jong and Lohr, 2007). The items are scored on 5-point Likert scale with 1 indicating "no disgust or repugnance at all" and 5 indicating "extreme disgust or repugnance". In this study the results were used on the sub-scales measuring disgust toward injections \& blood and death. Cronbach alpha for the factor of disgust toward injections \& blood in this study was $\alpha=.88$, and for disgust toward death was $\alpha=.83$.

Tendency Toward Alternative Medical Habits Questionnaire (Čović, Ivanković, Olujić and Šaravanja, 2015) consists of 9 items measuring a subject's inclination toward alternative medical procedures and supplements (eg "Whenever I visit a general doctor, I try to find an alternative way to treat the pain I feel" or "I go to bioenergy treatments"). The items are scored on a 5-point Likert scale with 1 indicating "strongly disagree" and 5 indicating "strongly agree" and the higher score indicates higher tendency 
toward alternative medical habits. Cronbach alpha in this study was rather low, but still acceptable $\alpha=.65$.

Propensity of Belief in Conspiracy Theories Questionnaire (Čović et al., 2015) originally consists of 20 items, but for the purpose of this study, 8 items were included that refer only toward propensity of belief in conspiracy theories regarding the pharmaceutical industry. The items are scored on a 5-point Likert scale and the higher score indicates higher propensity of belief in such conspiracy theories. Cronbach alpha in this study is $\alpha=.91$.

\section{Results}

Table 1 shows descriptive data collected with the used instruments.

Based on the Hogan Drug Attitude Inventory, the results indicate that the majority of participants evaluated themselves as pharmacophilics $(79.7 \%$ ) while the remaining $20.3 \%$ of participants consider themselves as pharmacophobics.

The results of all scales that were used in this study significantly deviate from normal, however, skewness and kurtosis coefficients do not indicate any extreme deviations. For that reason, it is justified to use parametric statistics (Kline, 2005).

In order to determine which variables explain the variance of pharmacophobia, hierarchical regression analysis was performed.
The results of this analysis are presented in Table 3, while the correlations between all variables are presented in Table 2 . The results showed that pharmacophobia correlates with most measured

variables except with demographic variables and variables measuring disgust toward injections \& blood and death.

The selected set of predictors explained $39 \%$ of the variance of pharmacophobia, where the greatest contribution in explaining the variance of pharmacophobia was belief in medication $(p<.01)$. Other significant predictors are drug form preferences (solid drug forms and drug forms intended for introduction into the body cavities) and propensity of belief in conspiracy theories. The more the person expressed a negative attitude toward medication and the more they expressed propensity of belief in conspiracy theories, the expressed pharmacophobia was also greater. Also, pharmacophobia is more expressed when there is a lesser preference toward solid drug forms and drug forms intended for introduction into the body cavities.

\section{Discussion}

In this study, $20.3 \%$ of participants declared themselves as pharmacophobics while the other $79.7 \%$ of participants considered themselves pharmacophilics. This ratio is not surprising given the fact that previous studies yielded similar ratios (Gazerani, 2017). Obtained results indicate that the greatest contribution in explaining

Table 1. Descriptive statistics and distribution parameters

\begin{tabular}{lccccccc} 
& M & SD & Min & Max & skewness & kurtosis \\
Pharmacophobia & -5.2 & 6.75 & -25 & 23 & .46 & .99 & $.089^{* *}$ \\
Liquid drug forms & 5.2 & 2.49 & 2 & 10 & .34 & -.91 & $.120^{* *}$ \\
\hline Solid drug forms & 23.6 & 7.10 & 5 & 40 & -.01 & -.34 & $.043^{* *}$ \\
Body cavities drug forms & 11.1 & 4.47 & 4 & 20 & .26 & -.65 & $.081^{* *}$ \\
\hline Alternative medical habits & 25.2 & 5.49 & 9 & 41 & -.06 & -.159 & $.048^{* *}$ \\
Belief in conspiracy theories & 20.3 & 7.59 & 8 & 40 & .28 & -.70 & $.074^{* *}$ \\
\hline Disgust toward injections \& blood & 11.8 & 5.88 & 6 & 30 & 1.15 & .63 & $.164^{* *}$ \\
Disgust toward death & 16.9 & 5.03 & 5 & 25 & -.37 & .09 & -.66 \\
\hline Belief about medicine & 23.4 & 6.22 & 8 & 40 & .04 & $.090^{* *}$ \\
\hline
\end{tabular}

$\mathrm{N}=700 ;{ }^{*} \mathrm{p}<.05,{ }^{* *} \mathrm{p}<.01$.

Table 2. Correlation coefficients.

\begin{tabular}{|c|c|c|c|c|c|c|c|c|c|c|c|c|}
\hline & 1 & 2 & 3 & 4 & 5 & 6 & 7 & 8 & 9 & 10 & 11 & 12 \\
\hline 1 Pharmacophobia & -- & -.02 & .03 & -.05 & $-.19 * *$ & $-.31^{* *}$ & $-.21^{* *}$ & $.27^{* *}$ & $.46^{* *}$ & $.08 *$ & .05 & $.58^{* *}$ \\
\hline 2 Gender & & -- & .03 & .03 & $.09 *$ & .05 & -.03 & $-.17^{* *}$ & $-.12^{* *}$ & $-.14^{* *}$ & $-.20 * *$ & $-.07 *$ \\
\hline 3 Age & & & -- & $.42^{* *}$ & $-.10 * *$ & $-.18 * *$ & $-.10^{* *}$ & $.21^{* *}$ & $.13^{* *}$ & -.01 & .05 & .04 \\
\hline 4 Education level & & & & -- & $-.09 * *$ & $-.08 *$ & $-.06 *$ & .05 & -.02 & -.05 & .03 & $-.07 *$ \\
\hline 5 Liquid drug forms & & & & & -- & $.52^{* *}$ & $.44^{* *}$ & -.03 & $-.11^{* *}$ & -.03 & -.01 & $-.07 *$ \\
\hline 6 Solid drug forms & & & & & & -- & $.48^{* *}$ & $-.13^{* *}$ & $-.25^{* *}$ & -.02 & -.01 & $-.22 *$ \\
\hline 7 Body cavities drug forms & & & & & & & -- & -.02 & $-.12^{* *}$ & -.05 & -.03 & $-.11^{* *}$ \\
\hline 8 Alternative medical habits & & & & & & & & -- & $.38^{* *}$ & $.10^{* *}$ & $.16^{* *}$ & $.38^{* *}$ \\
\hline 9 Belief in conspiracy theories & & & & & & & & & -- & $.11^{* *}$ & $.12^{* *}$ & $.63^{* *}$ \\
\hline 10 Disgust toward injections \& blood & & & & & & & & & & -- & $.50^{* *}$ & $.12^{* *}$ \\
\hline 11 Disgust toward death & & & & & & & & & & & -- & $.14^{* *}$ \\
\hline 12 Belief about medicine & & & & & & & & & & & & -- \\
\hline
\end{tabular}


the variance of pharmacophobia was belief in medication, as well as the significant contribution of the propensity of belief in conspiracy theories and drug form preference.

Regarding drug form preference, the obtained results showed that small to no preference of solid drug forms and the drug forms intended for introduction into the body cavities are predictors of pharmacophobia. The explanation of these results could be the fact that adults have more prescribed pills (coated and uncoated) and medications intended for introduction into the body cavities, rather than liquid medications. The consumption of these drug forms can be quite unpleasant and can cause aversion and avoidance of consumption when a doctor determines a particular therapy. Also, the fear of swallowing pills often occurs, which people may attempt to circumvent through various alternative ways of consumption such as crumbling pills or hiding them in food (eg bread, ice cream, etc.) (Garvie, Lensing and Rai, 2007). Although irrational, fear that the pill may physically hurt the person and that it is impossible to swallow additionally causes the decision not to take the prescribed doses of medication or to skip the prescribed therapy. The sensation during the pill consumption can be very unpleasant, the taste is not nice, and the whole idea that a pill is gradually being dissolved in a person's body is off-putting. Furthermore, drugs that are intended for introduction through body cavities are also not the most favored ones, especially in the case of medications administrated through the genital organs. The sensation is unpleasant, and the person could already have developed fear from previous experiences.

Although a negative correlation has been shown between all drug forms and pharmacophobia, liquid drug forms have not been shown as a significant predictor. Given the previous assumptions about the prescriptions of pills, these results can be expected. Liquid medications such as syrups or effervescent tablets are rarely prescribed to adults and can be considered as "children's" medication.

Although the results showed that the aversion toward solid drug forms and the medications intended for introduction through body cavities are predictors of pharmacophobia, it does not appear to be solely a physical fear of medication, but a combination of physical fear and a negative attitude toward medication in general. Physical fear can be potentiated by a negative attitude toward medicines in general, but also vice versa.
In present research, the predictor that has a great contribution in explaining the variance of pharmacophobia is propensity in belief in conspiracy theories about the pharmaceutical industry. Belief in conspiracy theories can contribute toward negative attitudes to medication and can result in developing a fear. A negative belief about the substance of the medication and expressed distrust toward the pharmaceutical industry could lead toward drug aversion. As is the case with all firm attitudes, people with expressed negative attitudes and beliefs in conspiracy theories find it difficult to change their minds, and to change attitudes analytical thinking is required to suppress sceptical thinking and attitudes (Swami, Voracek, Stieger, Tran and Furnham, 2014). Given the importance of the consumption of medication when a person has health difficulties, with a person that has expressed belief in conspiracy theories, it is very important to intervene and to give the person concrete information about the subject of the conspiracy. Doctors should give their patients detailed information about the ingredients of medications, potential side effects and answer all questions they have. It is important to give patients accurate information so that they can develop a more positive attitude.

Participants in this study have expressed a negative attitude toward medications and medicine in general. Furthermore, belief about medications is shown as an important predictor of nonadherence to given therapies (Horne and Weinman, 1999), and in this study, it was confirmed as a predictor with the highest proportion in explaining the variance of pharmacophobia. Thus, the more negative the beliefs about medications the greater the likelihood of pharmacophobia. Moreover, it is important to highlight that previous research has shown that negative beliefs about medications are not related to the number of medications a person has been prescribed in the past or that are currently consuming, but are related to a perceived importance of that particular medication (Jamous et al., 2014). Therefore, if a person believes in the irrelevance of medication, it is more likely that they will not consume it or will try alternative methods. In those moments when a person believes the medication could be crucial to save them from unwanted outcomes (such as death), then they will decide to consume the medication despite their negative attitude toward it.

As noted above, the results showed that people who do not prefer medication at all, have a greater tendency to practice

Table 3. Regression analysis results.

\begin{tabular}{|c|c|c|c|c|}
\hline Predictors & $1^{\text {st }}$ step $(\beta)$ & $2^{\text {nd }}$ step $(\beta)$ & $3^{\text {rd }}$ step $(\beta)$ & $4^{\text {th }}$ step $(\beta)$ \\
\hline Gender & -.020 & -.005 & .061 & .040 \\
\hline Age & .059 & .002 & -.071 & -.044 \\
\hline Education level & -.074 & $-.079 *$ & -.044 & -.020 \\
\hline Liquid drug forms & & -.023 & -.045 & -.057 \\
\hline Solid drug forms & & $-.263 * *$ & $-.156^{* *}$ & $-.119 * *$ \\
\hline Body cavities drug forms & & -.081 & $-.078^{*}$ & $-.070^{*}$ \\
\hline Alternative medical habits & & & $.131^{* *}$ & .053 \\
\hline Belief in conspiracy theories & & & $.371^{* *}$ & $.127^{* *}$ \\
\hline Disgust toward injections \& blood & & & & .016 \\
\hline Disgust toward death & & & & -.034 \\
\hline Belief about medicine & & & & $.446^{* *}$ \\
\hline Adjusted $\mathrm{R}^{2}$ & .001 & $.099 * *$ & $.269 * *$ & $.380^{* *}$ \\
\hline$\Delta \mathrm{R}^{2}$ & .006 & $.101^{* *}$ & $.170 * *$ & $.113^{* *}$ \\
\hline $\mathrm{F}$ & 1.336 & $13.798^{* *}$ & $33.084^{* *}$ & $40.024^{* *}$ \\
\hline
\end{tabular}

$\mathrm{N}=700 ;{ }^{*} \mathrm{p}<.05,{ }^{* *} \mathrm{p}<.01$. 
alternative medical solutions. However, although there is a positive correlation between alternative health habits and pharmacophobia, regression analysis did not confirm its contribution in explaining the variance of pharmacophobia. The reason for such results could be that its contribution is fully mediated through beliefs about medicine, where the person who has negative beliefs about medicines in general is more likely to turn toward alternative medicine methods. We hypothesized that sociodemographic data such as gender, age and education level could contribute to the explanation of pharmacophobia. Previous research has yielded contradictory results related to sociodemographic data and in this research none of the sociodemographic data appeared to be significantly associated with pharmacophobia. One possible explanation for the lack of such a finding could be the specificity of our sample, which mostly consisted of women, young people and those who have obtained a higher education level.

\section{Implications for further investigations}

Since the study was conducted with an online survey, it is important to emphasize all the limitation it carries, starting with the participants' self-selection and the representativeness of the sample. Future research should include participants of a broader age range and an equal percentage of participants by gender to make the results as representative as possible.

Despite these limitations, this study has important implications for recognition of pharmacophobia and future research. There are not many studies regarding pharmacophobia, but its importance has been recognized over the past few years. Recognizing pharmacophobia on time is of great importance so that specific prevention programs of interventions can be organized if needed. Also, in the future research, in addition to the quantitative part, it would be interesting to include a qualitative part of the research in order to be able to describe specifically how a negative drug belief, belief in conspiracy theories and propensity toward alternative medical habits interplay in explaining pharmacophobia.

\section{Conclusions}

In this study, with the aim to investigate predictors of pharmacophobia, on a sample of 700 participants, $20.3 \%$ of participants declared themselves as pharmacophobics. The greatest contribution in explaining the variance of pharmacophobia was negative belief in medication, as well as the significant contribution of the propensity of belief in conspiracy theories related to the pharmaceutical industry and drug form preference.

\section{References}

Bogart, L. M., Galvan, F. H., Wagner, G. J. \& Klein, D. J. (2011). Longitudinal association of HIV conspiracy beliefs with sexual risk among black males living with HIV. AIDS and Behavior, 15(6), 1180-1186. DOI: 10.1007/s10461-010-9796-7

Bradamante V., Klarica, M. \& Šalković-Petrišić, M. (2008). Farmakološki priručnik - drugo prošireno izdanje. Zagreb: Medicinska Naklada.

Čović, M., Ivanković, I., Olujić, O. i Šaravanja, N. (2015). Što kada bi cijepljenje bilo stvar izbora? Istraživanje o stavovima, znanjima $i$ drugim aspektima odluke o cijepljenju u Republici Hrvatskoj. Accessed April 16, 2018. Available from: http://darhiv. ffzg.unizg.hr/id/eprint/5899/1/Covic_Ivankovic_Olujic_Saravanja_
posebna_Rektotova_nagrada.pdf

Christudas, M. J., Gupta, B. S., Undela, K., Isaac, N. M., Ram, D. \& Ramesh, M. (2016). Assessment of impact of pharmacophilia and pharmacophobia on medication adherence in patients with psychiatric disorders: A cross-sectional study. Indian Journal of Pharmacology, 48(6), 701-705. DOI: 10.4103/0253-7613.194858

De las Cuevas, C. \& Peñate, W. (2015). Explaining pharmacophobia and pharmacophilia in psychiatric patients: relationship with treatment adherence. Human Psychopharmacology: Clinical and Experimental, 30, 377-383. DOI: 10.1002/hup.2487

Garvie, P. A., Lensing, S. i Rai, S. N. (2007). Efficacy of a pillswallowing training intervention to improve antiretroviral medication adherence in pediatric patients with HIV/AIDS. Pediatrics, 119(4), 893-899. DOI: 10.1542/peds.2006-1488

Gazerani, P. (2017). Pharmacophobia and pharmacophilia in alangesic use. Pain Management, 7(5), 341-344. DOI: 10.2217/pmt-2017-0015

Hogan, T. P., Awad, A. G \& Eastwood, R. (1983). A self-report scale predictive of drug compliance in schizophrenics: reliability and discriminative validity. Psychological Medicine, 13, 177-183. DOI: https://oi.org/10.1017/S0033291700050182

Horne, R. \& Weinman, J. (1999). Patients' beliefs about prescribed medicines and their role in adherence to treatment in chronic physical illness. Journal of psychosomatic research, 47(6), 555-567. DOI: 10.1016/s0022-3999(99)00057-4

Horne, R., Weinman, J. \& Hankins, M. (1999). The beliefs about medicines questionnaire: the development and evaluation of a new method for assessing the cognitive representation of medication. Psychology and health, 14(1), 1-24. DOI: https://doi.org/ 10.1080/08870449908407311

Jamous, R. M., Sweileh, W. M., Taha, A. S. E. D. A. i Zyoud, S. E. H. (2014). Beliefs About Medicines and Self-Reported Adherence Among Patients with Chronic Illness: A Study in Palestine. Journal of Family Medicine and Primary Care, 3(3), 224-229. DOI: 10.4103/2249-4863.141615

Kline, R. B. (2005). Principles and practice of structural equation modeling. New York: The Guilford Press.

Olatunji, B. O., Sawchuk, C. N., de Jong, P. J. i Lohr, J. M. (2007). Disgust Sensitivity and Anxiety Disorder Symptoms: Psychometric Properties of the Disgust Emotion Scale. Journal of Psychopathology and Behavioral Assessment, 29, 115-124. DOI: https://doi.org/10.1007/s10862-006-9027-8

Oliver, J. E. \& Wood, T. (2014). Medical conspiracy theories and health behaviors in the United States. JAMA internal medicine, 174(5), 817-818. DOI: 10.1001/jamainternmed.2014.190

Rettenbacher, M. A., Burns, T., Kemmler, G. \& Fleischhacker, W. W. (2004). Schizophrenia: Attitudes of Patients and Professional Carers Towards the Illness and Antipsychotic Medication. Pharmacopsychiatry, 37(3), 103-109. DOI: 10.1055/s-2004-818987

Sibitz, I., Katschnig, H., Goessler, R., Unger, A. \& Amering, M. (2005). Pharmacophilia and Pharmacophobia: Determinants of Patient's Attitudes towards Antipsychotic Medication. Pharmacopsychiatry, 38, 107-112. DOI: $10.1055 / \mathrm{s}-2005-864119$

Swami, V., Voracek, M., Stieger, S., Tran, U. S. i Furnham, A. (2014). Analytic thinking reduces belief in conspiracy theories. Cognition, 133(3), 572-585. DOI: 10.1016/j.cognition.2014.08.006

Vermeire, E., Hearnshaw, H., Van Royen, P. \& Denekens, J. (2001). Patient adherence to treatment: three decades of research. A comprehensive review. Journal of clinical pharmacy and therapeutics, 26(5), 331-342. DOI: 10.1046/j.1365-2710.2001. 00363.x

Walls, M. M., \& Kleinknecht, R. A. (1996, April). Disgust factors as predictors of blood-injury fear and fainting. In annual meeting of the Western psychological Association, San Jose, CA. 